\title{
Şehiriçi Yollarda Üstyapıların Mevcut Performansını Belirlemek İçin Bir Yöntem
}

\author{
Ufuk KIRBAŞ ${ }^{1}$ \\ Mustafa KARAŞAHIN ${ }^{2}$
}

Öz

Şehiriçi yolların üstyapılarını yöneten sistem(ler)in bulunması zorunluluğu kaçınılmazdır. Üstyapıların yönetimini sağlamak amacıyla kurulan bir sistemde en zor olan adımın, üstyapıların mevcut performansını belirlemek olduğu bilinmektedir. Üstyapıların yapısal performansı ile sürüş konforu arasında güçlü bir ilişkinin olduğu yapılan birçok çalışmada saptanmıştır. Çalışmada, bir karayolu üstyapısının mevcut performansını gösteren PCI değerleri ile araç içinde oluşan düşey titreşim parametreleri arasındaki ilişkiler araştırılarak tahmin modeli oluşturulmuştur. Böylelikle, üstyapının performansını belirlemede kullanılan PAVER sisteminin zor ve meşakkatli olan arazi çalışmaları minimuma indirilerek, ülkemizde yerel yönetimlerin üstyapı yönetiminde kullanabileceği hale getirilmiştir.

Anahtar Kelimeler: Üstyapı yönetim sistemi, ISO 2631-1, titreşim, paver sistemi, PCI.

\begin{abstract}
A Method for Determining Existing Pavement Performance in Urban Roads

The obligation of establishing system(s) that manage the suitability of road pavements in urban roads is inevitable. In a system which is established with the aim of ensuring the management of the pavements, the most difficult step is known to be determining the performance of the existing pavements. Many studies identified that there is a strong relationship between the structural performance of the pavements and the ride quality. In this study a prediction model was created by investigating the relationships between PCI that indicates the existing performance of a road pavement, and the vertical vibration parameters experienced inside the vehicle. Thus, the difficult and arduous terrain works of the PAVER system used for determining the pavement performance has been reduced by this work and a system has been made available for local governments to be used for pavement management.
\end{abstract}

Keywords: Pavement management system, ISO 2631-1, vibration, paver system, PCI.

\footnotetext{
Not: Bu yaz1

- Yayın Kurulu'na 16.02.2015 günü ulaşmıştır. 25.07.2017 günü yayımlanmak üzere kabul edilmiştir.

- 31 Temmuz 2018 gününe kadar tartışmaya açıktır.

- DOI: 10.18400/tekderg.373899

1 Ondokuz Mayıs Üniversitesi, İnşaat Mühendisliği Bölümü, Samsun - ufuk.kirbas@omu.edu.tr

2 İstanbul Gelişim Üniversitesi, İnşaat Mühendisliği Bölümü, İstanbul - mkarasahin@gelisim.edu.tr
} 


\section{GİRIŞ}

Karayolu ağlarında güvenlik ve konforu sağlayan en önemli unsurun yol üstyapısı olduğu bilinmektedir. Bir üstyapıdan olması gerektiği gibi faydalanabilmek için belirli aralıklarda planlı bir şekilde bakım ve onarımlar yapmak şarttır. Ülkemizde şehiriçi yolların yol yapım, bakım, onarım ve işletmesinden sorumlu olan yerel yönetimlerin belediyeler olduğu bilinmektedir. Genel olarak belediyelerde, üstyapı yapım, bakım ve onarım ile ilgili sorumluluklar ana arter ve daha yüksek önemdeki şehiriçi yollarda büyükşehir veya il merkezi türü belediyelerde iken, önem düzeyi ana arterin altındaki olan yollarla ilçe belediyelerindedir.

Üstyapıların mevcut performansları çeşitli teknikler kullanılarak belirli indeksler aracılığıyla sayısal olarak ifade edilebilmektedir [1]. İndeks değerlerine ulaşmada kullanılan yöntemler karmaşık olmanın yanında oldukça yüksek altyapı yatırımları da gerektirmektedir [2]. Özellikle orta ve küçük ölçekli belediyelerin bu maliyetleri karşılayabilmeleri çoğunlukla mümkün olmamaktadır. Çalışmada, bir üstyapı yönetim sisteminde (ÜYS) en zor adım olan üstyapıların mevcut performansını belirleyebilmek için oldukça kolay ve göreceli olarak ucuz bir yöntem önerilmiştir. Aynı zamanda bu yöntemle teknik şartnamelerde yer almayan, yeni imal edilen üstyapıların sürüş konforu açısından kalite kontrolü de yapılabilecektir.

\section{2.ÜSTYAPI YÖNETIM KAVRAMI}

ÜYS planlama, programlama, tasarım, yapım, bakım, onarım ve yenileme işlemlerinin tamamını içeren çalışma programıdır [3]. ÜYS kavramı, 1950’li yıllardan beridir çalışılan, teknolojinin gelişmesi ile yeniliklere kavuşarak günümüze gelmiş bir konudur. Amerikan mühendislik standartlarından biri olarak ASTM E1889 - 97(2009) koduyla ÜYS standardı da yayınlanmıştır [4].

Ulusal yol ağlarında üstyapının mevcut performansını belirlemek için genellikle cihazlarla yapılan ölçümlerin kullanıldığı görülmektedir. $\mathrm{Bu}$ maksatla, çoğunlukla yüzey pürüzlülüğünü ifade eden uluslararası düzgünsüzlük indeksinin (IRI) kullanıldığı çalışmalarda görülmektedir. Dünya Bankası tarafından geliştirilen standart çerçevesinde değerlendirilen IRI'ın üstyapı tasarımında kullanılan hizmet düzeyi (PSI) ile doğrudan ilişkili olduğu çalışmalarda belirtilmektedir [1,5]. Üstyapı değerlendirmelerinde ikinci olarak defleksiyon verilerinin (FWD) tercih edildiği anlaşılmaktadır. Benzer şekilde, şehiriçi yollarda da ÜYS çalışmalarının yapıldığı bilinmektedir. Damman (Arabistan), Lizbon (Portekiz) ve Amerika'da Bowling Green (Kentucy), Chittenden (Vermont), Dublin (Ohio), Folsom (California), Los Angeles (California) gibi daha birçok şehirin ÜYS çalışmalarını anlatan kaynak bulunmaktadır [6, 7]. Şehiriçi yollarda üstyapıların mevcut performansını belirlemede çoğunlukla yüzey bozulma verilerinin tercih edildiği görülmektedir. Ağırlıklı olarak tercih edilen indekslerin üstyapı durum indeksi (PCI), üstyapı durum oranı (PCR), üstyap1 yüzey değerlendirme ve oranlama sistemi (PASER) ve kalan servis ömrü (RSL) indekslerinin olduğu belirlenmiştir $[1,2,8]$.

Ayrıca, ivmeölçerler yardımıyla üstyapının mevcut performansını belirleme konusunda araştırmacıların, ağırlıklı olarak üstyapıdaki yüzey bozulma verileri ve/veya düzgünsüzlük verileri ile aracın düşey yöndeki titreşim verilerinin karşılaştırılması konusuna yöneldiği görülmektedir. Çalışmalarda, ivme verilerinin araç dinamiği modellerinde titreşim verisi 
olarak veya yüzey bozulma verileri ve düzgünsüzlük verileri ile korelasyonlarının araştırılmasında kullanıldığı belirlenmiştir. Dahası, bu ilişkiler matematiksel olarak oldukça iyi ifade edilebilmelerinden dolayı sürüş konforunu gerçek zamanlı olarak yansıtabilen sürüş simülasyon sistemlerinin oluşturulduğu yapılan çalışmalarda görülmektedir. Diğer bir deyişle günümüz teknolojisi kullanılarak tasarımı yapıldıktan sonra imal edilecek bir üstyapıda zamanla oluşacak bozulmalar ve bu bozulmaların sürücülere etkisi ile yolun hizmet seviyesinin henüz yol yapılmadan belirlenebileceği anlaşılmaktadır [9-13].

\section{METODOLOJI}

PAVER sistemi, rastgele dağılım prensiplerine göre seçilen örnek alanlarda, ASTM D 643311 kodlu bozulma tanımlama kılavuzuna göre toplanan yük, iklim ve diğer sebeplerden kaynaklanan bozulma verilerinin değerlendirilerek, üstyapının mevcut performansını ortaya koyan bir değerlendirme prosedürüdür [2, 14]. PAVER sisteminde $0-100$ arasında bir değerle üstyapıların mevcut performansını gösteren PCI değeri olarak 100 hiç bozukluk bulunmayan en iyi derecedeki üstyapıyı 0 ise tamamen bozulmuş kullanılamayacak derecedeki üstyapıyı ifade etmektedir. PCI, üstyapıya ait bozulma tipi, bozulma yoğunluğu ve bozulma miktarı bileşenlerinin ortak değerlendirilmesi sonucunda üstyapının mevcut performansını gösteren bir indekstir. Çalışmada, Samsun ili sınırlarında farklı türde belediyelerin sorumluluğunda, farklı hizmet seviyelerindeki 20 adet karayolunda ve 98 adet kesimde, diğer bir deyişle yaklaşık olarak $55.750 \mathrm{~m}$ uzunluğundaki yolda PAVER sistemine göre üstyapıların mevcut performansları belirlenmiştir. Değerlendirme kesimlerinin seçiminde veri çeşitliği ve model doğruluğunu arttırmak için farklı tipte, farklı yoğunluk düzeyinde ve farklı miktarlarda bozulmaların görülebilmesi kriterlerine dikkat edilmiştir.

Üstyapıların yüzey düzgünsüzlüğünün araç içerisinde düşey doğrultuda ölçülen titreşim ile yüksek derecede ilişkili olduğu bilinmektedir [10]. Literatürde araştırmacılar tarafından titreşim verilerini, konforu ifade etmek amacıyla analiz etmek için en çok ISO 2631-1 kodlu standartın tercih edildiği görülmektedir $[15,16]$. Standartta taşıt içinde maruz kalınan 3 boyutlu ivme ölçüm verilerinin farklı pozisyonlarda (oturarak, ayakta durarak ve sırt üstü uzanarak) ölçüm noktaları ile ortalama titreşimi yansıtan ağırlıklandırılmış karekök ortalama $\left(\mathrm{a}_{\mathrm{w}}\right)$ ve mekanik şokları yansıtan maksimum aktarılan titreşim değeri (MTVV) değerlendirme parametrelerinin hesap prensipleri açıklanmaktadır. Standart tüm vücudun maruz kaldığ titreşimi değerlendirebilmek için ivmeölçerin sürücünün hemen altında, sürücü ile temas halinde ve kauçuk bir yatak içerisinde olması gerektiğini tavsiye etmektedir. İvme ölçümleri 1/3 oktav bantlarına ayrılarak ve frekans ağırlık filtrelerinde tanımlanan kazançları uygulanarak, ilgili eksen doğrultusunda ağırlıklandırılmış toplam titreşim değerleri $\left(a_{w}\right)(1)$ nolu bağıntı ile elde edilir.

$\mathrm{a}_{\mathrm{w}}=\left[\sum_{\mathrm{i}}\left(\mathrm{w}_{\mathrm{i}} \mathrm{a}_{\mathrm{i}}\right)^{2}\right]^{\frac{1}{2}}$

Burada $\mathrm{a}_{\mathrm{w}}$, frekans ağırlıklandırılmış ivmeyi, $\mathrm{w}_{\mathrm{i}}$, ilgili frekans tanımlanan ağırlık faktörünü, $a_{i}$ ise $i$ inci $1 / 3$ oktav bandı için ivmelenme ortalama karekök değerini göstermektedir [15]. ISO 2631-1 standartına göre hareketli karesel ortalama (the runnig rms method) değerlendirme yöntemi sabit kısa zaman aralıklarında oluşan rastlantısal şok ve kişiye aktarılan titreşimlerin değerlendirmesinde uygulanan yöntemdir. Belirlenen bir zaman 
aralığında oluşan $\mathrm{a}_{\mathrm{w}}\left(\mathrm{t}_{0}\right)$ değerinin maksimumu bulunarak MTVV parametresi üretilmektedir. $\mathrm{a}_{\mathrm{w}}\left(\mathrm{t}_{0}\right)$ (2) ve MTVV (3) nolu bağıntı ile ifade edilmektedir.

$\mathrm{a}_{\mathrm{w}}\left(\mathrm{t}_{0}\right)=\left\{\frac{1}{\tau} \int_{\mathrm{t}_{0}-\tau}^{\mathrm{t}_{0}}\left[\mathrm{a}_{\mathrm{w}}(\mathrm{t})\right]^{2} \mathrm{dt}\right\}^{\frac{1}{2}}$

$\mathrm{MTVV}=\max \left[\mathrm{a}_{\mathrm{w}}\left(\mathrm{t}_{0}\right)\right]$

Burada $\mathrm{a}_{\mathrm{w}}(\mathrm{t})$, anlık frekans ağırlıklandırılmış ivmelenme değerini $\tau$, hareketli ortalama zaman dilimini $t$, ölçüm değişkenini ve $t_{0}$, ölçüm zamanını ifade etmektedir.

Çalışmada üç adet ivmeölçer, GPS anteni ve veri kayıt cihazı (datalogger)'ndan oluşan ivme ölçüm seti ile aynı yollarda düşey doğrultudaki titreşim verileri kaydedilmiştir. Kaydedilen titreşim verileri ISO 2631-1 standardına göre değerlendirilmiş, PCI değerleri belirlenen yol kesimlerinde $a_{w}$ ve MTVV değerleri elde edilmiştir. Düşey titreşim ölçümleri, Euro Car segment değerlendirmesine göre $4100-4600 \mathrm{~mm}$ uzunluk aralı̆ı̆nda alt orta sinıf C segmentine giren station wagon türünde bir araçla yapılmıştır. Ölçümler sırasında ivmeölçerler, sürücü koltuğu (üzerinde sürücü var) ve orta aks üzeri (ayak hizası) olmak üzere üç farklı noktaya yerleştirilmiştir. Ölçümler sırasında taşıtın sabit bir şeritte, sabit bir hızda ve en az $20 \mathrm{~km} / \mathrm{sa}$ hızda olması ölçüm kriterleri olarak kabul edilmiştir [5].

En uygun ölçüm hızını belirlemek amacıyla farklı tür ve yoğunlukta bozulmaların görüldüğü bir yolda düşey ivme ölçümleri 20, 30, 40 ve $50 \mathrm{~km} / \mathrm{sa}$ hızlarda her şerit için ayrı ayrı yapılmıştır. Öte yandan, yapılan değerlendirmenin geliştirilmesi için aracın mekanik yapısından kaynaklı oluşan düşey titreşimlerin etkisinden kurtulmak amacıyla, boyuna eğimi sıfıra yakın ve yüzey bozulması hiç olmayan yeni imal edilmiş bir yolda $(\mathrm{PCI}=100)$ her bir ölçüm hızı için ve her bir ölçüm noktası için ayrı ayrı kalibrasyon parametreleri üretilmiştir. Böylece, herhangi bir yolda yapılan ölçüm sonrasında bulunan parametrik titreşim değerlerinden kalibrasyon için bulunan parametrik titreşim değerlerinin çıkarılması ile düzeltilmiş titreşim parametreleri (düz.a $a_{w}$, düz.MTVV) bulunmuştur.

Kesimlerin PCI değerleri ile sürücü koltuğu $\mathrm{a}_{\mathrm{w}}$ parametresi değerleri arasında yapılan istatistik değerlendirmelerde en yüksek korelasyonun $40 \mathrm{~km} / \mathrm{sa}$ hızda oluşmasından dolayı en uygun ölçüm hızı olarak $40 \mathrm{~km} / \mathrm{sa}$ kabul edilmiştir [17]. Fakat uygulamada, şehiriçi trafik koşullarında, belirli bir şeritte tam olarak belirli bir hızda gitmenin trafik, yolların boyuna eğimi gibi geometrik kısıtlar vb. muhtelif sebeplerle sabit hızın korunmasının mümkün olmadığ1 görülmüştür. Ölçümler sırasında, cihaz dahilinde bulunan gps anteni ile bir saniye aralıkla hız verileri de kaydedilmiştir. Dolayısıyla değerlendirmede, 1 sn aralıklarla toplanan araç hızının aritmetik ortalaması kesimin ortalama hızı olarak kabul edilmiş ve kesimlere ait hız bileşenleri elde edilmiştir.

\section{DEĞERLENDİRMELER}

Çalışmada, kesimlerin PCI değerini ivme ölçümlerinden tahmin edebilen bir regresyon modeli oluşturulmuştur. Öncelikle yapılan analizlerin birbirlerine karşı rölatif doğrulukları incelenmiş̧tir. Güvenirlik analizinde kullanılan modellerden biri de Alfa Modelidir. Alfa $(\alpha)$ katsayısına bağlı olarak ölçeğin güvenirliği $0.00 \leq \alpha<0.40$ ise ölçek güvenilir değildir, 0.40 
$\leq \alpha<0.60$ ise ölçeğin güvenirliği düşük, $0.60 \leq \alpha<0.80$ ise ölçek güvenilir ve $0.80 \leq \alpha<$ 1.00 ise ölçek yüksek derecede güvenilir bir ölçek olduğu kabul edilmektedir [18]. Sürücü koltuğu ve orta aks üzeri ölçüm noktalarında titreşim ölçümünden üretilen $a_{w}$ ve MTVV titreşim parametrelerinin hı faktörü ile birlikte veya ayrı olacak şekilde değerlendirilmesiyle her kesim için 8 adet farklı parametre üretilmiştir. Parametrelerin alfa değeri $\alpha=0.841$ olarak bulunmuştur. Verilerin 'yüksek derecede güvenilir' olduğu sonucuna ulaşılmıştır. Bu parametrelerin birbirlerine göre korelasyonları Çizelge 1.'de görülmektedir. Aşağıdaki çizelgede alt indislerden SK= Sürücü Koltuğu, OAU= Orta Aks Üzeri ölçüm yerlerinde yapılan titreşim ölçümlerinden üretilen parametreleri göstermektedir.

Çizelge 1. Modelleme çalışmasında kullanılacak parametreler ve korelasyonlar.

\begin{tabular}{|c|c|c|c|c|c|c|c|c|}
\hline & düz.âw SK & $\begin{array}{c}\text { düz.a } \\
\text { OAU }\end{array}$ & $\begin{array}{l}\text { düz.a } \mathbf{a}_{\mathrm{w}} \mathrm{sK} \\
/ \ln (\mathrm{Hız})\end{array}$ & $\begin{array}{c}\text { düz.a } \\
\text { oAU } \\
/ \ln (\text { Hız }) \\
\end{array}$ & $\begin{array}{c}\text { düz.MTVV } \\
\mathrm{SK}_{\mathrm{K}}\end{array}$ & $\underset{\substack{\text { düz.MTV } \\
\text { OAU }}}{ }$ & $\begin{array}{c}\text { düz.MTVV } \\
\quad / \ln (\mathrm{H} ı z)\end{array}$ & $\begin{array}{c}\text { düz.MTVV OAU } \\
\quad / \ln (\mathrm{HIz})\end{array}$ \\
\hline düz.a $a_{w} s K$ & 1.000 & 0.930 & 1.000 & 0.927 & 0.708 & 0.648 & 0.711 & 0.650 \\
\hline düz.aw $O A U$ & 0.930 & 1.000 & 0.932 & 0.999 & 0.586 & 0.692 & 0.591 & 0.696 \\
\hline $\begin{array}{l}\text { düz.a }{ }_{w} \text { sk } \\
\text { / /n(Hız) }\end{array}$ & 1.000 & 0.932 & 1.000 & 0.930 & 0.703 & 0.644 & 0.707 & 0.647 \\
\hline $\begin{array}{l}\text { düz.aw oAU } \\
/ \ln \left(\mathrm{H}_{\mathrm{zz}}\right) \\
\end{array}$ & 0.927 & 0.999 & 0.930 & 1.000 & 0.579 & 0.686 & 0.584 & 0.691 \\
\hline düz.MTVV $\mathrm{sk}$ & 0.708 & 0.586 & 0.703 & 0.579 & 1.000 & 0.802 & 1.000 & 0.799 \\
\hline $\begin{array}{l}\text { düz.MTVV } \\
\text { OAU }\end{array}$ & 0.648 & 0.692 & 0.644 & 0.686 & 0.802 & 1.000 & 0.802 & 1.000 \\
\hline $\begin{array}{l}\text { düz.MTVV } \mathrm{sk} \\
/ \ln (\mathrm{Hzz})\end{array}$ & 0.711 & 0.591 & 0.707 & 0.584 & 1.000 & 0.802 & 1.000 & 0.800 \\
\hline $\begin{array}{l}\text { düz.MTVV } \\
\text { oAU / /n(Hız) }\end{array}$ & 0.650 & 0.696 & 0.647 & 0.691 & 0.799 & 1.000 & 0.800 & 1.000 \\
\hline
\end{tabular}

Çizelge 1'de korelasyonların oldukça yüksek ve birbirlerine yakın olduğu görülmektedir. Bu durumun, regresyon analizinde oldukça sık karşılaşılan kolinerite (bağımlılık) problemiyle karşılaşıımasına neden olacağı için adım adım her bir değişken ayrı ayrı değerlendirilerek PCI tahmin modeli oluşturulmuştur.

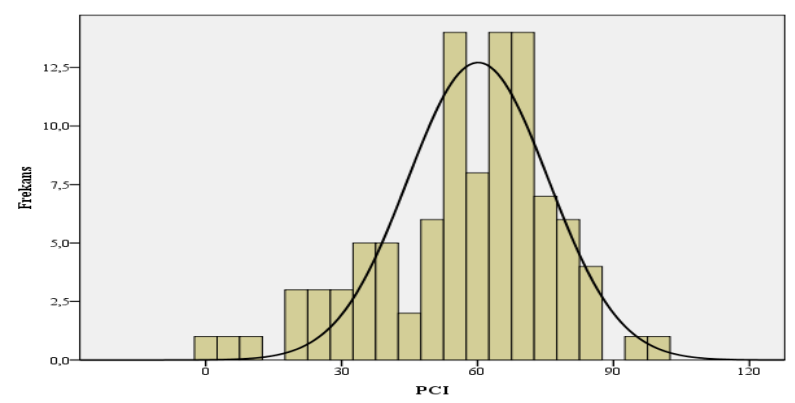

Şekil 1. PCI değerlerinin normal dă̆llım histogramı. 
Bir regresyon modelinin kurulmasında modellenecek bağımlı değişkenin normal dağılıma uygun olması gerekmektedir. $\mathrm{Bu}$ amaçla, tahmin modelinde bağımlı değişken PCI değerlerinin normal dağılıma uygunluğunu test etmek amaciyla tek örneklem kolmogorov smirnov testi uygulanmıştır. Değerlendirme sonucunda, çift kuyruklu anlamlılık değeri 0.175 $>0.05$ bulunarak PCI değerlerinin \%95 güven aralığında normal dağılıma uygun olduğu saptanmıştır. Ayrıca, histogram grafiği aşağıdaki Şekil 1'de görülmekte olan PCI değerlerinin önemli miktarda çarpıklık arz etmemektedir.

Yapılan değerlendirmeler sonucu ölçüm hızı, sürücü koltuğu üzeri düz. $a_{w}$ ve orta aks üzeri düz. $a_{w}$ ve düz.MTVV bileşenlerinin en uygun değişkenler olduğu saptanmıştır. $\mathrm{Bu}$ değişkenlere bağlı olarak üretilen PCI tahmin modeli aşağıdaki şekildedir.

$\mathrm{PCI}=\frac{-453.472 * \text { düz. } \mathrm{a}_{\mathrm{w}} \mathrm{SK}}{\ln (\mathrm{H} \mathrm{z})}+\frac{-196.310 * \text { düz. } \mathrm{a}_{\mathrm{w}} \mathrm{OAU}}{\ln (\mathrm{H} \mathrm{z})}+5.227 *$ düz.MTVV $_{\mathrm{OAU}}+94.508$

Burada düz. $\mathrm{a}_{\mathrm{w}}$ sk bileşeni düzeltilmiş $\mathrm{a}_{\mathrm{w}}$ Sürücü Koltuğu'nu $\left(\mathrm{m} / \mathrm{sn}^{2}\right)$, düz. $\mathrm{a}_{\mathrm{w}}$ OAU bileşeni

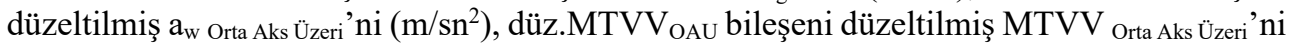
$\left(\mathrm{m} / \mathrm{sn}^{2}\right)$ ve Hız bileşeni kesimin ortalama ölçüm hızını $(\mathrm{km} / \mathrm{sa})$ göstermektedir. Bağımlı ve bağımsız değişkenler arasında regresyon değeri $0.874(\mathrm{R}=0.935)$ gibi oldukça yüksek bir ilişki yakalanabilmiştir. Gerçek ve model kullanılarak elde edilen PCI değerleri arasındaki farklar grafik olarak Şekil 2'de görülmektedir.

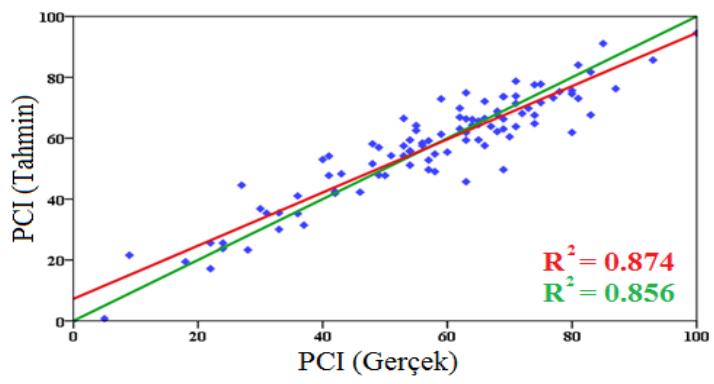

Şekil 2. PCI değerleri arasındaki farklar.

Çizelge 2. PCI Tahmin Modeli istatistik verileri

\begin{tabular}{|c|c|c|c|c|c|c|c|}
\hline & \multicolumn{2}{|c|}{ Sabitler } & \multirow{2}{*}{$\mathrm{t}$} & \multirow{2}{*}{ Anlam. } & \multicolumn{2}{|c|}{ Korelasyonlar } & \multirow{2}{*}{$\frac{\text { Kolinerite }}{\text { Kondüsyon İn }}$} \\
\hline & Katsayılar & Std. Hata & & & PCI ile & Anlam. & \\
\hline Sabit & 94.508 & 1.824 & 51.817 & .000 & & & 1 \\
\hline $\begin{array}{l}\text { düz.aw SK } \\
/ \ln (\mathrm{H} ı z)\end{array}$ & -453.472 & 73.158 & -6.199 & .000 & -.923 & .000 & 5.496 \\
\hline $\begin{array}{l}\text { düz.aw OAU } \\
/ \ln \left(H_{1 z}\right)\end{array}$ & -196.310 & 49.460 & -3.969 & .000 & -.904 & .000 & 7.088 \\
\hline düz.MTVV OAU & 5.227 & 2.264 & 2.309 & .023 & -.563 & .000 & 17.371 \\
\hline
\end{tabular}


Oluşturulan modele ait istatistik parametreler Çizelge 2'de görülmektedir. Gerek katsayılarda gerekse korelasyon değerlerinde istatistik anlamlılık değeri 0.05 'den küçük yani, bulunan sonuçların istatistik olarak \%95 anlamlılık sınırında olduğu görülmektedir. $\mathrm{Bu}$ değerlendirmeye göre bağımsız değişkenler arasında önemli bir kolinerite probleminin olmadı̆̆ı görülmektedir.

\section{SONUÇ VE ÖNERILER}

Üstyapıların mevcut performansının sürüş konforunu en iyi yansıttığı kabul edilen, araç içinde oluşan düşey doğrultudaki titreşim değerleri ile yapılabileceği düşünülmüştür. Çalışmada, PAVER sisteminin zor ve meşakkatli olan arazi çalışmalarının azaltılması hedeflenmiştir. Nihai çıktı olarak, PCI değerini titreşim verileri aracılığıyla tahmin edebilen tahmin modeli oluşturulmuştur. Regresyon yöntemi kullanılarak geliştirilen modelde, eldeki verilerin model kurulması açısından zaruri istatistiki kısıtları sağladığı tespit edilmesinden sonra ölçüm hızı, sürücü koltuğu düz. $a_{w}$, orta aks üzeri düz.a $a_{w}$ ve düz.MTVV bağımsız değişkenlerini kullanan bir PCI tahmin modeli üretilmiştir. Tahmini ve gerçek veriler arasında $0.8738(\mathrm{R}=0.935)$ gibi oldukça yüksek bir doğrusal ilişki yakalanabilmiştir.

Üretilen model yardımıyla herhangi bir yerel yönetimin sorumluluğunda bulunan, üstyapıları bitümlü sıcak karışım türündeki bir karayolu ağına ait ağ düzeyinde bir ÜYS kurmasının oldukça kolay ve işlevsel olacağı düşünülmektedir. Şüphesiz ki yapılan bu çalışma yardımıyla hayata geçirilecek bir ÜYS çerçevesinde kesimlere ait bakım\&onarım veya yenileme uygulama projelerinin oluşturulabilmesi için yerinde gözlem ve ölçümlerin yapılması gerekmektedir.

\section{Semboller}

\begin{tabular}{|c|c|}
\hline PCI & : Üstyap1 performans indeksi (Pavement Condition Index); \\
\hline$a_{w}$ & : Frekans Ağırlıklandırılmış Karekök Ortalama ivme; \\
\hline $\mathrm{a}_{\mathrm{w}}\left(\mathrm{t}_{0}\right)$ & : Bir zaman aralığında frekans ağırlıklandırılmış karesel ortalama; \\
\hline$\tau$ & : Hareketli ortalama zaman dilimini; \\
\hline $\mathrm{t}$ & : Ölçüm değişkenini; \\
\hline$t_{0}$ & : Ölçüm zamanı; \\
\hline$\alpha$ & : Cronbach alfa katsayısı; \\
\hline MTVV & : Maksimum Aktarılan Titreşim Değeri; \\
\hline düz. $\mathrm{a}_{\mathrm{w} S \mathrm{SK}}$ & : Sürücü koltuğu düzeltilmiş $\mathrm{a}_{\mathrm{w}}$ parametresi $\left(\mathrm{m} / \mathrm{sn}^{2}\right)$; \\
\hline düz.a $a_{w}$ OAU & : Orta aks üzeri düzeltilmiş $\mathrm{a}_{\mathrm{w}}$ parametresi $\left(\mathrm{m} / \mathrm{sn}^{2}\right)$; \\
\hline düz.MTVV ${ }_{S K}$ & : Sürücü koltuğu düzeltilmiş MTVV parametresi (m/sn²); \\
\hline düz.MTVV $\mathrm{OAU}_{\mathrm{O}}$ & : Orta aks üzeri düzeltilmiş MTVV parametresi $\left(\mathrm{m} / \mathrm{sn}^{2}\right)$; \\
\hline Hiz & : Kesimin ortalama ölçüm hızı (km/sa); \\
\hline
\end{tabular}




\section{Teşekkür}

Yazarlar çalışmaya desteğinden dolayı İstanbul Üniversitesi Bilimsel Araştırma Projeleri birimine teşekkür eder.

\section{Kaynaklar}

[1] Haas, R., Hudson, W.R., Zaniewski, J.P., Modern Pavement Management, Krieger Pub. Co., Malabar, Florida, USA, 1994.

[2] Shahin, M.Y., Pavement Management for Airports, Roads, and Parking Lots, Springer, New York, 2005.

[3] Kırbaş, U., Karaşahin, M., Performance Models For Hot Mix Asphalt Pavements In Urban Roads, Construction and Building Materials, 116, 281-288, 2016.

[4] ASTM, E1889-97: Standard Guide for Pavement Management Implementation, ASTM International, West Conshohocken, PA, 2009.

[5] ASTM, E 950: Standard Test Method for Measuring the Longitudinal Profile of Traveled Surfaces with an Accelerometer Established Inertial Profiling Reference, ASTM International, West Conshohocken, PA, 2009.

[6] Wolters, A., Zimmerman, K., Schattler, K., Rietgraf, A., Implementing Pavement Mangement System for Local Agencies, Research Rep., Illinois, ICT-11-094-1, 2011.

[7] Picado-Santos, L., Ferreira, A., Antunes, A., Carvalheira, C., Santos, B., Bicho, M., Quadrado, I., Silvestre, S., Pavement Management System For Lisbon, Thomas Telford Ltd, pp. 157-165, 2004.

[8] Shahin, M.Y., Kohn, S.D., Pavement Maintenance Management for Roads and Parking Lots, Research Rep., U.S. Army Construction Engineering Res. Lab., 1981.

[9] Terzi, S., Modeling for Pavement Roughness Using the ANFIS Approach, Advances in Engineering Software, 57, 59-64, 2013.

[10] Cantisani, G., Loprencipe, G., Road Roughness and Whole Body Vibration: Evaluation Tools and Comfort Limits, Journal of Transportation Engineering, 136(9), 818-826, 2010.

[11] Griffin, M.J., Discomfort From Feeling Vehicle Vibration, Vehicle System Dynamics, 45(7-8), 679-698, 2007.

[12] Ahlin, K., Granlund, N.O.J., Relating Road Roughness and Vehicle Speeds to Human Whole Body Vibration and Exposure Limits, International Journal of Pavement Engineering, 3(4), 207-216, 2002.

[13] Bolling, A., Jansson, J., Hjort, M., Lidström, M., Nordmark, S., Sehammar, H.k., Sjögren, L., An Approach for Realistic Simulation of Real Road Condition in a Moving Base Driving Simulator, Journal of Computing and Information Science in Engineering, 11(4), 41009, 2011.

[14] ASTM, D 6433-11: Standard Practice for Roads and Parking Lots Pavement Condition Index Surveys, ASTM International, West Conshohocken, PA, 2011. 
[15] ISO, 2631-1: Mechanical vibration and shock - Evaluation of human exposure to wholebody vibration, Part 1: General Requirement, ISO, Geneva, Switzerland, 1997.

[16] Griffin, M.J., Handbook Of Human Vibration, Academic Press, London, UK, 2012.

[17] Kırbaş, U., Şehiriçi Yollarda Üstyapı Bakım Yönetim Sistemi Kurulması, Türkiye Örneği, Doktora, Fen Bilimleri Enstitüsü, İstanbul Üniversitesi, 2013.

[18] Kalaycı, Ş., SPSS Uygulamalı Çok Değişkenli İstatistik Teknikleri, Asil Yayın Dağıtım, Ankara, 2006. 
